\title{
INCIDENCE OF ICU-ASSOCIATED PNEUMONIA IN PATIENTS ADMITTED TO ICU OF MAJOR TERTIARY CARE HOSPITALS
}

\footnotetext{
1. MBBS, MD (USA)

Resident Physician

District Medical Unit-I

DHQ Teaching Hospital, Sargodha

2. MBBS, MD (USA)

Resident Physician

Bronx Care Hospital Center, Bronx NY

3. MBBS MD (USA)

Resident Physician

Bronx care Hospital Center, Bronx, NY.

4. MBBS, MD (USA)

Resident Physician

UPMC McKeesport, USA

5. MBBS, FCPS

Consultant Physician

Supervisor CPSP

DHQ Teaching Hospital, Sargodha.
}

Correspondence Address:

Dr. Muhammad Khuram Nouman

House No.143 Mansoorabad Colony,

Sargodha.

khuram nouman@hotmail.com

Article received on:

16/08/2018

Accepted for publication:

$15 / 02 / 2019$

Received after proof reading:

$28 / 08 / 2019$

\begin{abstract}
Muhammad Khuram Nouman', Syed Arsalan Akhter Zaidi², Bushra Zaidi ${ }^{3}$, Kainat Saleem ${ }^{4}$,
\end{abstract} Muhammad Khan Malik

ABSTRACT... Objectives: Despite in techniques advancement to patient care for respiratory tracts are instrumented may complicate the IAP course up to $50 \%$ in patients with mechanical ventilation. It requires rapid diagnoses and treatment that is appropriate as per patient condition. Many studies revealed negative impact with delayed administration and antibiotic treatment in IAP patients may increase the hospital mortality and morbidity. The primary objective of the study was to estimate the incidence of IAP in the patient admitted in ICU of tertiary care hospitals in Rawalpindi Pakistan. Study Design: Observational cross sectional study. Setting: ICU units of various tertiary care hospitals in Rawalpindi, Pakistan. Period: One year from Dec 2016-Dec 2017. Materials and Methods: A total 450 subjects were enlisted for the study; these patients were selected randomly. The exclusion criteria include all patients with Acute Respiratory Distress Syndrome (ARDS) or those on long-term antibiotic or steroid therapy and all the pregnant women whereas all the patients of both sexes, kept on ventilator for more than $48 \mathrm{~h}$ and above the age of 18 years were included in this study. Results: We enrolled a total of 450 patients for this study. The average age of all the participants was $61.51+12.8$ with range $36-91.230(51.1 \%)$ of the patients were male whereas $220(48.9 \%)$ were females. The TraumaPulm contusion was absent in all patients. In ICU 150 (33.3\%) were diagnosed with COPD, 150(33.3\%) with Asthma, 220(48.9\%) with ARDS, 10 (2.2\%) with head trauma and $310(68.8 \%)$ with diabetes.200 (44.4\%) smokers, 40(8.8\%) were having lung cancer, 310(68.8\%) were hypertensive and 20 (4.4\%) were with Pneumothorax - requiring Chest Tube. Conclusion: We may conclude from our study that ICU associated Pneumonia is a serious issue, that developed with longer hospital stay, duration of mechanical ventilation and re-intubation. By reducing the mechanical ventilation duration, pneumonia can be controlled.

Key words: Hospital Stay, ICU Associated Pneumonia (IAP), Intensive Care Unit (ICU), Mechanical Ventilation Duration.

Article Citation: Nouman MK, Zaidi SAA, Zaidi B, Saleem K, Malik MK. "The incidence of ICU-associated pneumonia in patients admitted to ICU of major tertiary care hospitals". Professional Med J 2019; 26(9):1546-1550.

DOI: 10.29309/TPMJ/2019.26.09.4021

\section{INTRODUCTION}

Intensive care unit (ICU) associated Pneumonia (IAP) is usually a pneumonia developed among patients who were on mechanical ventilation more than 48 hours in ICU. ${ }^{1-2}$ The range varies from $0-60 \%$ and sometime $76 \%$ in certain conditions..$^{3-4}$ The IAP developed once after the patients get admitted to the ICU of tertiary care hospital. The presence of IAP can increase the hospital stay up to 10 days and more in patients admitted to ICU. .- $^{5-}$ ${ }^{6}$ This not only increases the hospitalization stay but also indirectly increases the patient's cost. To a certain report published in literature, it is said that the development of IAP increases 3\% per day during first week of mechanical ventilation. ${ }^{7-8}$ Despite in techniques advancement to patient care for respiratory tracts are instrumented may complicate the IAP course up to $50 \%$ in patients with mechanical ventilation. ${ }^{9}$ It requires rapid diagnoses and treatment that is appropriate as per patient condition. Many studies revealed negative impact with delayed administration and antibiotic treatment in IAP patients may increase the hospital mortality and morbidity. ${ }^{10}$ The primary objective of the study was to estimate the incidence of IAP in the patient admitted in ICU of tertiary care hospitals in Rawalpindi Pakistan. 


\section{MATERIAL AND METHODS}

We had opted the observational cross sectional design for the present study. A total 450 subjects were enlisted for the study; these patients were selected randomly from the ICU units of various tertiary care hospitals in Rawalpindi, Pakistan. The study duration was of one year from Dec 2016-Dec 2017. The exclusion criteria include all patients with Acute Respiratory Distress Syndrome (ARDS) or those on long-term antibiotic or steroid therapy and all the pregnant women whereas all the patients of both sexes, kept on ventilator for more than $48 \mathrm{~h}$ and above the age of 18 years were included in this study. The demographic information with necessary diagnostic history was collected for all the subjects after the attendant or person signed the consent form. For all diagnostic values, the standard operating procedures (SOPs) were strictly followed in hospital laboratory. The blood sugar, blood pressure was measured and assigned a diabetic or non-diabetic status same hypertensive and non-hypertensive. The hospitalization stay and the outcomes were also noted. The ethical approval was taken from the college and hospital ethical Committee.

\section{Statistical Analysis}

All the information collected or noted from patients were than entered electronically to MS EXCELL sheets and stored in computer. Latterly this data was prepared for SPSS and analyzed by using version 20. Descriptive statistics were applied by calculating mean and standard deviation. Frequency distribution and percentages were performed for all qualitative variables like gender, Diabetes, Pneumonia etc. $P$ values less than 0.05 was considered statistically significant in all inferential statistics.

\section{RESULTS}

We enrolled a total of 450 patients for this study. The average age of all the participants was 61.51 +12.8 with range $36-91$. $30(6.6 \%)$ of the patient were in the age category of 36 to 44 . $70(15.5 \%)$ belong to $45-54$ and $180(40 \%)$ were above 5564 years of age.170 (37.7\%) of the patients were above and equal to 65 years of age. 230(51.1\%) of the patients were male whereas $220(48.9 \%)$ were females. $180(40 \%)$ of the patients were in public hospitals, $90(20 \%)$ were in private and $180(40 \%)$ were in semi public hospitals. The detailed summary of presenting complaints can be seen in Figure-1.

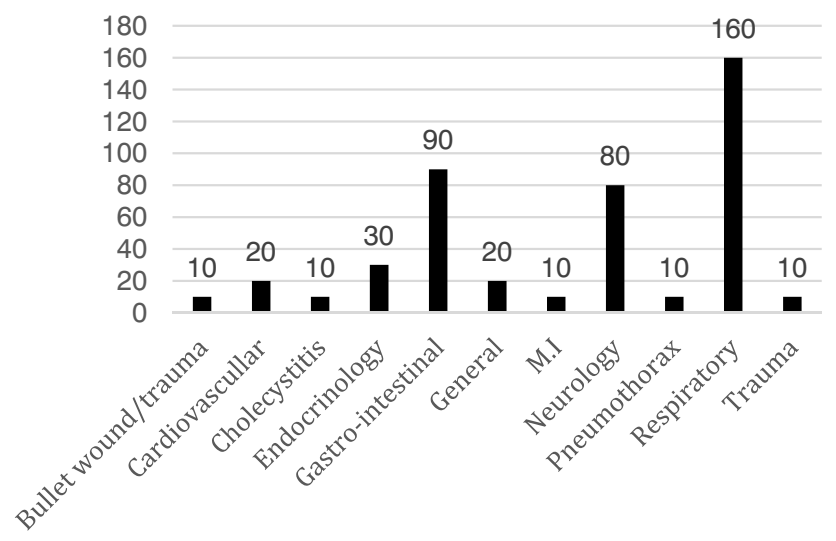

Figure-1. Frequency of presenting complaints in patients.

The Trauma-Pulm contusion was absent in all patients. In ICU 150 (33.3\%) were diagnosed with COPD, 150(33.3\%) with Asthma, 220(48.9\%) with ARDS, 10 (2.2\%) with head trauma and 310 (68.8\%) with diabetes. 200 (44.4\%) smokers, $40(8.8 \%)$ were having lung cancer, $310(68.8 \%)$ were hypertensive and 20 (4.4\%) were with Pneumothorax - requiring Chest Tube. More on the patient's outcomes and findings is given in Table-I.

\begin{tabular}{|l|c|}
\hline \multicolumn{1}{|c|}{ Patient's Findings/Outcome } & $\mathbf{n}(\%)$ \\
\hline Ventilator associated pneumonia & $280(62 \%)$ \\
\hline ICU length of Stay (average) & 10.42 days \\
\hline Trach or ETT & \\
\hline ETT & $400(89 \%)$ \\
\hline Trach & $50(11 \%)$ \\
\hline $\begin{array}{l}\text { Average Days on MV after which } \\
\text { pneumonia developed }\end{array}$ & 4.46 days \\
\hline Re-intubations & $140(31 \%)$ \\
\hline Position - Supine / Semi-Recumbent & \\
\hline Supine & $250(56 \%)$ \\
\hline Semi-Recumbent & $200(44 \%)$ \\
\hline Conscious on admission & $360(80 \%)$ \\
\hline Sedation & $380(85 \%)$ \\
\hline Broad spectrum Abx & $220(49 \%)$ \\
\hline Oral Antiseptics & $220(49 \%)$ \\
\hline Antacids & $50(11 \%)$ \\
\hline H2 Blockers & $320(72 \%)$ \\
\hline Sucrulfate & $90(20 \%)$ \\
\hline PRBC transfusion & $80(18 \%)$ \\
\hline OG/NG Tube & $300(67 \%)$ \\
\hline Table-I. A detailed summary of patient's findings or \\
\hline
\end{tabular}


At three month follow up $120(26.6 \%)$ patients had expired. The evaluation of risk in various risk factors was done in Table-II.

\begin{tabular}{|c|c|c|}
\hline Risk Factors & $\begin{array}{l}\text { Incidence of } \\
\text { Pneumonia }\end{array}$ & P-Value \\
\hline ETT & $62 \%$ & \multirow{2}{*}{0.81} \\
\hline Trach & $67 \%$ & \\
\hline \multicolumn{2}{|l|}{ Re-Intubations } & \multirow{3}{*}{0.000} \\
\hline Yes & $100 \%$ & \\
\hline No & $47 \%$ & \\
\hline \multicolumn{2}{|l|}{ PRBC Transfusion } & \multirow{3}{*}{0.41} \\
\hline Yes & $75 \%$ & \\
\hline No & $59 \%$ & \\
\hline \multicolumn{2}{|l|}{ Sedation } & \multirow{3}{*}{0.004} \\
\hline Yes & $71 \%$ & \\
\hline No & $14 \%$ & \\
\hline \multicolumn{3}{|c|}{$\begin{array}{l}\text { Table-II. The detailed summary of the risk } \\
\text { assessment (incidence of Pneumonia) }\end{array}$} \\
\hline Preventive Measures & $\begin{array}{l}\text { Incidence of } \\
\text { Pneumonia }\end{array}$ & $P=$ Value \\
\hline \multicolumn{2}{|l|}{ Sucrulfate } & \multirow{3}{*}{0.009} \\
\hline Yes & $100 \%$ & \\
\hline No & $53 \%$ & \\
\hline \multicolumn{2}{|l|}{ H2 Blockers } & \multirow{3}{*}{0.000} \\
\hline Yes & $47 \%$ & \\
\hline No & $100 \%$ & \\
\hline \multicolumn{2}{|l|}{ Antacids } & \multirow{3}{*}{0.38} \\
\hline Yes & $80 \%$ & \\
\hline No & $60 \%$ & \\
\hline \multicolumn{2}{|l|}{ Oral Antiseptics } & \multirow{3}{*}{0.001} \\
\hline Yes & $27 \%$ & \\
\hline No & $96 \%$ & \\
\hline \multicolumn{2}{|l|}{ Broad Spectrum Abx } & \multirow{3}{*}{0.84} \\
\hline Yes & $64 \%$ & \\
\hline No & $61 \%$ & \\
\hline
\end{tabular}

\section{DISCUSSION}

This study was planned to determine the ICU associated Pneumonia in patients admitted to ICU of various tertiary care hospitals in Rawalpindi. We not only estimated the pneumonia incidence but also identify the patient's outcome once on mechanical ventilator in ICU. We had reported in our study the ICU associated pneumonia overall incidence of $62 \%$. This incidence is slightly higher to other published studies. ${ }^{11,8}$ This may be due to the population difference, geographical differences and difference in use of preventive strategies. The average ICU stay length was almost 11 days reported in our study. This also an elevated stay, the probable reasons could be the insufficiency and experience of the staff nurses in the tertiary care hospital, thus this study also highlighted the insufficiency of paramedical staff may increase the length of stay of patients alongside to the physical condition of the patient. This is very much comparable to the situation in other developing countries. ${ }^{12}$ Under current causal conditions, we have observed in our study that the respiratory and gastro-intestinal complaints were commonest that patients present while on ventilation. Trauma was also observed in patients that could be considered in pneumonia development. Similar findings were observed in various published reports. ${ }^{9}$ In few studies the commonest factor was the injury like head and multiple fractures were commonest in their population. ${ }^{13-14}$ Considering the other risk factors, we reported in our study the longer hospitalization stay and duration of mechanical ventilation as most important factors for pneumonia development. It is observed in this study the patients who were on mechanical ventilation for a period of above ten days had developed more pneumonia than those who were on less than ten days. Similar findings were reported by an Italian study with above 700 ICU patients concluding the ICU associated pneumonia were arisen 5\% among patients on mechanical ventilation for a day to reach above $60 \%$ for those where the ventilation period was set up to 30 days. ${ }^{15-19}$ Another risk factor was the trach and ETT factor, it was observed in high incidence in our population. $\mathrm{H} 2$ blockers, broad-spectrum Abx and Oral antiseptics were also commonest and associated to the pneumonia development. We found similar findings in a study held in France, where antimicrobial therapy significantly raised the ICU associated Pneumonia. ${ }^{10}$ We reported in our findings that the risk of getting Pneumonia is high in patients who went intubation, with Sucrulfate and in a sedated condition with $p$ values $(0.000$, $0.009,0.004$ respectively), Whereas the risk is high if the patient is not taking any oral antiseptics and with no $\mathrm{H} 2$ blockers with $\mathrm{p}$ value less than 0.05 . The difference is not statistical significant 
in case of PRBC transfusion but the incidence is high among those patients who underwent PRBC transfusion i.e. $75 \%$.

\section{CONCLUSIONS}

We may conclude from our study that ICU associated Pneumonia is a serious issue, that developed with longer hospital stay, duration of mechanical ventilation and re-intubation. By reducing the mechanical ventilation duration, pneumonia can be controlled.

Copyright@ 15 Feb, 2019.

\section{REFERENCES}

1. Davis KA. Ventilator-associated pneumonia: A review. J Intensive Care Med. 2006; 21:211-26.

2. Al-Shameri, Faroq A. “Critical care nurse's knowledge of ventilator-associated pneumonia prevention in selected hospitals, khartoum." Nursing \& Healthcare International Journal. 2017: 1 (5).

3. Balk, R. Adherence to ventilator-associated pneumonia bundle and incidence of ventilatorassociated pneumonia in the surgical intensive care unit. Yearbook of Critical Care Medicine, 2011, 140-41.

4. Koenig SM, Truwit JD. Ventilator-associated pneumonia: Diagnosis, treatment, and prevention. Clin Microbiol Rev. 2006; 19:637-57.

5. Chastre J, Fagon JY. Ventilator-associated pneumonia. Am J Respir Crit Care Med. 2002; 165:867903.

6. Rello J, Ollendorf DA, Oster G, Montserrat V, Bellm $\mathrm{L}$, Redman R, et al. Epidemiology and outcomes of ventilator-associated pneumonia in a large US database. Chest. 2002; 122:2121.

7. Badawy, M. Evaluation of risk factors of ventilator associated pneumonia on outcome of acute exacerbation of COPD. Chest, 2016:150(4).

8. Rodrigues DO, Cezário RC, Filho PP. Ventilatorassociated pneumonia caused by multidrugresistant Pseudomonas aeruginosa vs. Other microorganisms at an adult clinical-surgical intensive care unit in a Brazilian University Hospital: Risk factors and outcomes. Int J Med Med Sci. 2009; 1:432-7.
9. Chastre J, Fagon JY. Ventilator-associated pneumonia. Am J Respir Crit Care Med. 2002; 165:867903.

10. Young D, Harrison DA, Cuthbertson BH, Rowan K. Effect of early vs late tracheostomy placement on survival in patients receiving mechanical ventilation: the TracMan randomized trial. Jama. 2013 May 22;309(20):2121-9.

11. Iregui M, Ward S, Sherman G, Fraser VJ, Kollef MH. Clinical importance of delays in the initiation of appropriate antibiotic treatment for ventilatorassociated pneumonia. Chest. 2002; 122:262-8.

12. Morehead RS, Pinto SJ. Ventilator-associated pneumonia. Arch Intern Med. 2000; 160:1926-36.

13. Hugonnet S, Uçkay I, Pittet D. Staffing level: A determinant of late-onset ventilator-associated pneumonia. Crit Care. 2007; 11:R80.

14. Sampathkumar, P. Nosocomial pneumonia. Critical Care Surgery. 2010: 195-209.

15. Charles, M. P. Incidence and risk factors of ventilator associated pneumonia in a Tertiary Care Hospital. Australasian Medical Journal. 2013 6(4), 17882.

16. Aggarwal, V. Outcomes of mechanically ventilated critically ill geriatric patients in intensive care unit. Journal of Clinical and Diagnostic Research. 2017: 140:302-5.

17. Al-Alaiyan S, Binmanee A. Neonatal VentilatorAssociated Pneumonia: An Underdiagnosed Problem in the Neonatal Intensive Care Units. J Pediatr Neonatal Care. 2017;7(3):00288.

18. Joseph NM, Sistla S, Dutta TK, Badhe AS, Rasitha $D$, Parija SC. Ventilator-associated pneumonia in a tertiary care hospital in India: Role of multi-drug resistant pathogens. J Infect Dev Ctries. 2010; 4:21825.

19. Gupta A, Agrawal A, Mehrotra S, Singh A, Malik S, Khanna A. Incidence, risk stratification, antibiogram of pathogens isolated and clinical outcome of ventilator associated pneumonia. Indian J Crit Care Med. 2011; 15:96-101. 


\begin{tabular}{|c|l|l|c|}
\multicolumn{4}{|c|}{ AUTHORSHIP AND CONTRIBUTION DECLARATION } \\
\hline Sr. \# & \multicolumn{1}{|c|}{ Author-s Full Name } & \multicolumn{1}{c|}{ Contribution to the paper } & Author=s Signature \\
\hline 1 & M. Khuram Nouman & 1st Author & \\
2 & Syed Arsalan Akhter Zaidi & 2nd Author & \\
\hline 3 & Bushra Zaidi & 3rd Author & \\
4 & Kainat Saleem & 4th Author & \\
\hline 5 & Muhammad Khan Malik & 5th Author & \\
\hline
\end{tabular}

